\title{
Evaluation of dose effects of magnesium sulfate on rocuronium injection pain and hemodynamic changes by laryngoscopy and endotracheal intubation
}

\author{
Young Hee Shin, Soo Joo Choi , Hui Yeon Jeong, and Myung Hee Kim \\ Department of Anesthesiology and Pain Medicine, Samsung Medical Center, Sungkyunkwan University School of Medicine, Seoul, Korea
}

Background: Rocuronium produces injection pain in $50-80 \%$ of treated patients. Therefore, a variety of pretreatments have been attempted to reduce this issue. We evaluated the efficacy of 3 different doses of magnesium on the rocuronium injection pain and following hemodynamic changes by laryngoscopy and tracheal intubation (LTI).

Methods: Two hundreds patients, ASA I and II, undergoing general anesthesia for elective surgery were randomly divided to 4 groups: group 1, 2, 3, 4 received saline $5 \mathrm{ml}$, magnesium 5,10 and $20 \mathrm{mg} / \mathrm{kg}$ prior to $0.6 \mathrm{mg} / \mathrm{kg}$ of rocuronium, respectively. Then, group 1 only was treated with esmolol $(20 \mathrm{mg})$ before LTI. Pain intensity with rocuronium injection was assessed using a four-point scale according to patient's movement. Cardiovascular responses at baseline, after induction, 1 minutes after LTI were determined.

Results: Compared to saline, 10 and $20 \mathrm{mg} / \mathrm{kg}$ of magnesium significantly reduced the incidence of overall movement after rocuronium injection ( $34 \%$ and $36 \%$ in group 3 and 4 , respectively vs. $76 \%$ in the group 1$)(\mathrm{P}<0.0001)$. Generalized movement was seen in $4 \%$ of patients in groups 3 and 4, respectively. Compared to baseline values, diastolic blood pressure (DBP) immediately after LTI significantly increased within groups 1 and $2(\mathrm{P}<0.001)$, but not within groups 3 and 4 .

Conclusions: Magnesium (10 and $20 \mathrm{mg} / \mathrm{kg}$ ) prior to rocuronium was effective in attenuating rocuronium associated injection pain and cardiovascular changes by LTI. (Korean J Anesthesiol 2011; 60: 329-333)

Key Words: Cardiovascular response, Magnesium sulfate, Rocuronium injection pain, Tracheal intubation.

Received: September 24, 2010. Revised: October 19, 2010. Accepted: November 4, 2010.

Corresponding author: Myung Hee Kim, M.D, Ph.D., Department of Anesthesiology and Pain Medicine, Samsung Medical Center, Sungkyunkwan University School of Medicine, 50, Ilwon-dong, Kangnam-gu, Seoul 135-710, Korea. Tel: 82-2-3410-2470, Fax: 82-2-3410-0361, E-mail: mhsmc. kim@samsung.com

(c) This is an open-access article distributed under the terms of the Creative Commons Attribution Non-Commercial License (http:// creativecommons.org/licenses/by-nc/3.0/), which permits unrestricted non-commercial use, distribution, and reproduction in any medium, provided the original work is properly cited. 


\section{Introduction}

As a non-depolarizing muscle relaxant, rocuronium is useful for endotracheal intubation due to rapid onset time, but it produces injection pain, which is often associated with withdrawal movement of the injected hand or arm, in 50$80 \%$ of injected patients [1]. Even in unconsciousness patients administered with anesthetic induction agents, rocuronium causes withdrawal movement, indicating intense pain [2]. Therefore, a variety of pretreatments have been attempted to reduce the rocuronium injection pain. Turan et al. [3] demonstrated that a small dose of magnesium, average $7 \mathrm{mg} / \mathrm{kg}$, reduced rocuronium injection pain effectively compared to lidocaine, sodium bicarbonate and alfentanil.

As a calcium channel blocker and a physiological antagonist of the N-methyl-D-aspartate (NMDA) receptors magnesium has reduced the anesthetic requirement during surgery and analgesics for postoperative pain control [4-7]. Although the exact mechanism is not clear, magnesium was also demonstrated to have a local analgesic effect in reducing injection pain by intravenous propofol [8,9] and rocuronium [3].

After muscle relaxation with rocuronium, subsequent laryngoscopy and tracheal intubation (LTI) causes inevitable hemodynamic changes such as hypertension and tachycardia. Magnesium has also been suggested as a useful strategy in attenuating the adrenergic response to LTI $[10,11]$. However, in those studies, the authors used 50 or $60 \mathrm{mg} / \mathrm{kg}$ of magnesium to attenuate the hemodynamic response to LTI. That dose was much larger than the required amount of magnesium to reduce rocuronium injection pain. To date, few studies have investigated the effective doses of magnesium, which can attenuate both rocuronium injection pain and the following hemodynamic responses by LTI in general anesthesia.

Therefore, the aim of this study was to evaluate the effectiveness of pretreatment with magnesium using doses of 5, 10, and 20 $\mathrm{mg} / \mathrm{kg}$ for both the prevention of rocuronium injection pain and the attenuation of the resulting hemodynamic response after LTI.

\section{Materials and Methods}

After obtaining our institutional ethics committee approval and patients' written informed consent from each patient, 200 America Society of Anesthesiologists physical status classification (ASA) I-II patients undergoing various elective surgeries with general anesthesia were randomly divided to 4 groups (all $\mathrm{n}=50$ ). They received normal saline $5 \mathrm{ml}$ (group 1), magnesium sulfate 5,10 and $20 \mathrm{mg} / \mathrm{kg}$ (groups 2, 3 and 4), respectively, before rocuronium injection. To attenuate hemodynamic stimulation, $20 \mathrm{mg}$ of esmolol (methyl 3-4-[2-hydroxy-3-(isopropylamino) propoxyphenyl] propionate hydrochloride) was given to group 1 before LTI. Randomization was conducted by computer-generated codes that were maintained in sequentially numbered envelopes. Exclusion criteria were prior use of calcium channel blockers, opioids and anticoagulants, pregnancy, known allergy to magnesium sulfate, disorders of cardiovascular, hepatic, renal, gastrointestinal and neurological diseases, morbid obesity, and difficult airway. No premedication was given to any patients. Before the induction of anesthesia standard monitoring of heart rate, non-invasive arterial pressure, ECG and arterial oxygen saturation was initiated. All patients had an 18 gauge IV catheter on the forearm and all drugs were administered near the IV catheter. Anesthesia was induced with propofol $(2 \mathrm{mg} / \mathrm{kg})$. After finding the abolished eyelid reflex, either normal saline $5 \mathrm{ml}$, or magnesium sulfate $(5,10$, or $20 \mathrm{mg} / \mathrm{kg})$ prior to $0.6 \mathrm{mg} / \mathrm{kg}$ of rocuronium was administered over one minute according to the assigned groups. Intravenous fluid infusion was occluded for 30 seconds after magnesium injection in all groups. Mask ventilation with sevoflurane in $100 \%$ oxygen was maintained for 90 seconds after rocuronium injection, before LTI. Anesthesia after LTI was maintained with an end tidal sevoflurane concentration of $2-2.5 \%$ in a mixture of air and oxygen $50 \%$.

The patient's response, as feeling of pain or discomfort, to intravenous rocuronium injection was assessed by observing patient's movements, such as no movement (grade 0), movement only wrist (grade 1), movement to the upper arm and shoulder of injected arm (grade 2) or generalized movements (grade 3).

Hemodynamic variables such as systolic and diastolic blood pressure (SBP and DBP) and heart rate (HR) were recorded before the anesthetic induction (baseline value), before and 1 min after tracheal intubation.

Data are expressed as means \pm standard deviation (SD) or numbers of patients (percentages). Chi-square test or Fisher's exact test was used for sex ratio and degree of withdrawal movements during injection of rocuronium among the groups. One way analysis of variance (ANOVA) for age, weight and height. A mixed linear model with Bonferroni's correction within the groups and ANOVA with Bonferroni's correction among the groups for hemodynamic changes at all study stages, were used. $\mathrm{P}<0.05$ was considered statistically significant.

\section{Results}

The demographic data were comparable among all groups (Table 1). Administration of magnesium at 10 and $20 \mathrm{mg} /$ $\mathrm{kg}$ significantly reduced the incidence of overall movement compared to the saline control after rocuronium administration (34\% and $36 \%$ in the group 3 and 4 , respectively vs. $76 \%$ in 
group 1) ( $\mathrm{P}<0.0001$, for both comparisons). Withdrawal movement (grade 3 ), indicating severe pain, was seen in $4 \%$ of patients in both the magnesium $20 \mathrm{mg} / \mathrm{kg}$ and $10 \mathrm{mg} / \mathrm{kg}$ groups, respectively (both groups vs. saline, $\mathrm{P}<0.05$; both groups vs. magnesium $5 \mathrm{mg} / \mathrm{kg}, \mathrm{P}<0.05$ ) (Table 2).

The mean baseline values for SBP, DBP and HR were comparable among the groups (Table 3 ). The SBP and DBP values following anesthetic induction before intubation were significantly lower compared to baseline values within the groups ( $P<0.001$ in each group). LTI caused no increase of SBP and DBP with the administration of magnesium sulfate at $10 \mathrm{mg} / \mathrm{kg}$ or $20 \mathrm{mg} / \mathrm{kg}$ prior to intubation, but significant increases in DBP were seen with administration of esmolol (20 $\mathrm{mg}$ ) or magnesium sulfate $(5 \mathrm{mg} / \mathrm{kg}$ ) compared to baseline values within each groups $(\mathrm{P}<0.001)$. During anesthetic induction, HR was not different compared to baseline value within the groups. LTI caused a significant increase in HR compared to baseline values in all groups. Adverse effects such as severe hypotension or bradycardia was not seen in any patients following administration of either esmolol or magnesium at any doses before LTI. Although magnesium may potentiate neuromuscular blockade, it was assumed that the administration of magnesium sulfate $(5,10$ or $20 \mathrm{mg} / \mathrm{kg})$ did not

Table 1. Demographic Data

\begin{tabular}{lcccc}
\hline & $\begin{array}{c}\text { Control } \\
(\mathrm{n}=50)\end{array}$ & $\begin{array}{c}\text { Mg 5 } \\
(\mathrm{n}=50)\end{array}$ & $\begin{array}{c}\text { Mg 10 } \\
(\mathrm{n}=50)\end{array}$ & $\begin{array}{c}\text { Mg 20 } \\
(\mathrm{n}=50)\end{array}$ \\
\hline Gender (m/f) & $24 / 26$ & $25 / 25$ & $23 / 27$ & $24 / 26$ \\
Age (yr) & $41.7 \pm 11.5$ & $41.8 \pm 12.4$ & $39.8 \pm 13.4$ & $40.9 \pm 14.9$ \\
Weight (kg) & $65.0 \pm 13.3$ & $64.9 \pm 13.3$ & $65.9 \pm 12.1$ & $63.4 \pm 10.4$ \\
Height (cm) & $164.8 \pm 8.5$ & $164.9 \pm 9.3$ & $165.6 \pm 9.2$ & $165.3 \pm 10.5$
\end{tabular}

Values are mean \pm SD or numbers. $M g 5, M g 10$ and $M g 20$ indicate intravenous administration of the magnesium sulfate at doses of 5 $\mathrm{mg} / \mathrm{kg}, 10 \mathrm{mg} / \mathrm{kg}$ and $20 \mathrm{mg} / \mathrm{kg}$, respectively, before rocuronium injection. prolong muscular relaxation in this study, because no patient was delayed to resume of ventilation at the end of surgery.

\section{Discussion}

In this study, we found that intravenous pretreatment with 10 or $20 \mathrm{mg} / \mathrm{kg}$ of magnesium prior to rocuronium administration significantly alleviated rocuronium injection pain, $20 \mathrm{mg} /$ $\mathrm{kg}$ better than $10 \mathrm{mg} / \mathrm{kg}$. In addition, magnesium at 10 or 20 $\mathrm{mg} / \mathrm{kg}$ prior to rocuronium provided stable blood pressures immediately after LTI.

Rocuronium is an attractive muscle relaxant due to rapid onset of action, and it works as fast as succinylcholine. However, high incidence of hand or limb withdrawal or generalized movement is seen, indicating injection pain, even under anesthesia, which can be a considerable drawback for rocuronium. The mechanism by which rocuronium causes injection pain is speculative $[12,13]$. Therefore, to overcome rocuronium induced withdrawal movement, a various studies using different drugs have been investigated [12,14-16]. In this study, 10 and $20 \mathrm{mg} /$

Table 2. Assessment of Withdrawal Movement

\begin{tabular}{lrrcc}
\hline & $\begin{array}{c}\text { Control } \\
(\mathrm{n}=50)\end{array}$ & $\begin{array}{c}\text { Mg 5 } \\
(\mathrm{n}=50)\end{array}$ & $\begin{array}{c}\text { Mg 10 } \\
(\mathrm{n}=50)\end{array}$ & $\begin{array}{c}\text { Mg 20 } \\
(\mathrm{n}=50)\end{array}$ \\
\hline Grade 0 & $12(24 \%)$ & $14(28 \%)$ & $32(64 \%)^{*, \dagger}$ & $33(66 \%)^{*, \dagger}$ \\
Grade 1 & $10(20 \%)$ & $7(14 \%)$ & $8(16 \%)$ & $10(20 \%)$ \\
Grade 2 & $19(38 \%)$ & $16(32 \%)$ & $8(16 \%)$ & $5(10 \%)^{*}$ \\
Grade 3 & $9(18 \%)$ & $13(26 \%)$ & $2(4 \%)^{*, \dagger}$ & $2(4 \%)^{*, \dagger}$ \\
Overall & $38(76 \%)$ & $36(72 \%)$ & $18(36 \%)^{*}$ & $17(34 \%)^{*}$ \\
\hline
\end{tabular}

Values are numbers (\%). Grade 0, 1, 2 and 3 indicate no movement, movement only wrist, movement to the upper arm and shoulder of injected arm and generalized movements, respectively. $\mathrm{Mg} 5, \mathrm{Mg}$ 10 and $\mathrm{Mg} 20$ indicate intravenous administration of magnesium sulfate at doses of $5 \mathrm{mg} / \mathrm{kg}, 10 \mathrm{mg} / \mathrm{kg}$ and $20 \mathrm{mg} / \mathrm{kg}$, respectively, prior to rocuronium injection. $\mathrm{P}<0.05$ was considered statistically significant. ${ }^{*} \mathrm{P}<0.05$ vs group $1 .{ }^{\dagger} \mathrm{P}<0.05$ vs group 2 .

Table 3. Hemodynamic Data at All Observation Stages

\begin{tabular}{|c|c|c|c|c|c|}
\hline & & $\begin{array}{l}\text { Control } \\
(n=50)\end{array}$ & $\begin{array}{c}\operatorname{Mg} 5 \\
(n=50)\end{array}$ & $\begin{array}{c}\text { Mg } 10 \\
(n=50)\end{array}$ & $\begin{array}{c}\operatorname{Mg} 20 \\
(n=50)\end{array}$ \\
\hline \multirow[t]{3}{*}{ SBP (mmHg) } & Baseline & $133 \pm 19$ & $134 \pm 18$ & $133 \pm 19$ & $134 \pm 20$ \\
\hline & B-intubation & $112 \pm 17^{*}$ & $115 \pm 21^{*}$ & $111 \pm 16^{*}$ & $110 \pm 20^{*}$ \\
\hline & P-intubation $1 \mathrm{~min}$ & $133 \pm 21$ & $139 \pm 26$ & $131 \pm 22$ & $133 \pm 21$ \\
\hline \multirow[t]{3}{*}{ DBP (mmHg) } & Baseline & $73 \pm 12$ & $69 \pm 11$ & $72 \pm 13$ & $71 \pm 13$ \\
\hline & B-intubation & $61 \pm 12^{*}$ & $59 \pm 11^{*}$ & $59 \pm 13^{*}$ & $57 \pm 14^{*}$ \\
\hline & P-intubation 1 min & $81 \pm 19 *$ & $80 \pm 21^{*}$ & $76 \pm 18$ & $69 \pm 15$ \\
\hline \multirow[t]{3}{*}{ HR (beats/min) } & Baseline & $74 \pm 13$ & $74 \pm 14$ & $75 \pm 13$ & $77 \pm 13$ \\
\hline & B-intubation & $77 \pm 13$ & $77 \pm 13$ & $76 \pm 10$ & $81 \pm 15$ \\
\hline & P-intubation $1 \mathrm{~min}$ & $99 \pm 19 *$ & $108 \pm 16^{*}$ & $102 \pm 17^{*}$ & $105 \pm 15^{*}$ \\
\hline
\end{tabular}

Values are expressed as mean \pm SD. B-intubation: before intubation. P-intubation: post intubation. SBP: systolic blood pressure. DBP: diastolic blood pressure. HR: heart rate. $\mathrm{Mg} \mathrm{5,} \mathrm{Mg} 10$ and $\mathrm{Mg} 20$ indicate intravenous administration of magnesium sulfate at $5 \mathrm{mg} / \mathrm{kg}$, $10 \mathrm{mg} / \mathrm{kg}$ and $20 \mathrm{mg} / \mathrm{kg}$, respectively, prior to rocuronium injection. $\mathrm{P}<0.05$ was considered statistically significant. $* \mathrm{P}<0.05$ vs baseline value within each groups. 
$\mathrm{kg}$ of magnesium significantly reduced the overall incidence of movements associated with intravenous rocuronium, when compared to the saline control group. Generalized movement, indicating severe pain, was found only in $4 \%$ of patients administered magnesium at 10 or $20 \mathrm{mg} / \mathrm{kg}$.

Magnesium sulfate, known to be a natural calcium channel blocker, has shown to have antinociceptive effects via inhibition of calcium channels and NMDA receptors [5]. Therefore, magnesium has been considered as a useful anesthetic adjunct for intra- and postoperative analgesia in anesthetic practice $[4,6,7]$. The local analgesic effect of magnesium has also been suggested in previous studies. For example, magnesium reduced local injection pain associated with intravenous propofol [8,9] and rocuronium [3]. Agarwal et al. [8] suggested that pretreatment with $1 \mathrm{~g}$ of magnesium minimized propofol induced pain and was as effective as $40 \mathrm{mg}$ of lidocaine. In another comparison study aiming to prevent the injection pain by rocuronium, $2 \mathrm{ml}$ of $2.48 \mathrm{mmol}$ magnesium was found to be as effective as $30 \mathrm{mg}$ of lignocaine, $2 \mathrm{ml}$ of $8.4 \%$ sodium bicarbonate or $1,000 \mu \mathrm{g}$ of alfentanil [3]. However, since it has been suggested that pretreatment with magnesium itself causes pain [8], caution for slow administration of magnesium may be needed. But, administration of magnesium sulfate over one minute in this study did not demonstrate any pain on injection per se as well as circulatory collapse.

LTI after intubating dose of rocuronium produces marked increase in BP and HR due to catecholamine release. Because hemodynamic changes by LTI may be associated with serious medical conditions, various techniques including administration of magnesium, to attenuate the adrenergic responses by LTI have been investigated $[10,11,17]$. Pretreatment with intravenous magnesium $(40 \mathrm{mg} / \mathrm{kg}$ ) was reported as a helpful adjunct in reducing hemodynamic responses after succinylcholine facilitated tracheal intubation [17]. Further $60 \mathrm{mg}$ of magnesium sulfate effectively attenuated the catecholamine release and hemodynamic response after non-depolarizing muscle relaxant induced LTI [10]. In compromised patients with coronary artery disease, magnesium at $50 \mathrm{mg} / \mathrm{kg}$ before the induction of anesthesia resulted in stable hemodynamic responses to LTI compared to lidocaine [11]. In the current study, administration of magnesium (10 or $20 \mathrm{mg} / \mathrm{kg}$ ) prior to rocuronium to alleviate rocuronium injection pain also prevented the increase in blood pressure immediately after LTI. However, the significant increase in HR after LTI was not prevented with 10 or $20 \mathrm{mg} /$ $\mathrm{kg}$ of magnesium administration. Therefore, further studies to find the optimum dose of magnesium prior to rocuronium for inhibiting both rocuronium injection pain and the hemodynamic changes following LTI is needed. As a standard regimen to reduce hemodynamic changes by LTI in the control group, we used i.v. esmolol (20 mg) immediately before LTI [18]. A larger dose of esmolol was more effective in minimizing LTI induced responses, but it also showed a potential risk for severe bradycardia and hypotension in a low stress condition [19]. Therefore, we chose $20 \mathrm{mg}$ of esmolol before LTI as a dose that would prevent severe hypertension and tachycardia without inducing significant hypotension and bradycardia.

In conclusion, although a dose that controlled both the pain related to rocuronium and the hemodynamic responses to intubation was not determined in this study, we found doses of magnesium (10 and $20 \mathrm{mg} / \mathrm{kg}$ ) that alleviated the pain associated with rocuronium injection and as well as the changes in blood pressure after LTI.

\section{References}

1. Steegers MA, Robertson EN. Pain on injection of rocuronium bromide. Anesth Analg 1996; 83: 203.

2. Borgeat A, Kwiatkowski D. Spontaneous movements associated with rocuronium: is pain on injection the cause? Br J Anaesth 1997; 79: 382-3.

3. Turan A, Memis D, Karamanlioglu B, Sut N, Pamukcu Z. The prevention of pain from injection of rocuronium by magnesium sulphate, lignocaine, sodium bicarbonate and alfentanil. Anaesth Intensive Care 2003; 31: 277-81.

4. Koinig H, Wallner T, Marhofer P, Andel H, Hörauf K, Mayer N. Magnesium sulfate reduces intra- and postoperative analgesic requirements. Anesth Analg 1998; 87: 206-10.

5. McBain CJ, Mayer ML. N-methyl-D-aspartic acid receptor structure and function. Physiol Rev 1994; 74: 723-60.

6. Tauzin-Fin P, Sesay M, Delort-Laval S, Krol-Houdek MC, Maurette P. Intravenous magnesium sulphate decreases postoperative tramadol requirement after radical prostatectomy. Eur J Anaesthesiol 2006; 23: 1055-9.

7. Tramer MR, Schneider J, Marti RA, Rifat K. Role of magnesium sulfate in postoperative analgesia. Anesthesiology 1996; 84: 340-7.

8. Agarwal A, Dhiraj S, Raza M, Pandey R, Pandey CK, Singh PK, et al. Vein pretreatment with magnesium sulfate to prevent pain on injection of propofol is not justified. Can J Anaesth 2004; 51: 130-3.

9. Memiş D, Turan A, Karamanlioğlu B, Süt N, Pamukcu Z. The use of magnesium sulfate to prevent pain on injection of propofol. Anesth Analg 2002; 95: 606-8.

10. James MF, Beer RE, Esser JD. Intravenous magnesium sulfate inhibits catecholamine release associated with tracheal intubation. Anesth Analg 1989; 68: 772-6.

11. Puri GD, Marudhachalam KS, Chari P, Suri RK. The effect of magnesium sulphate on hemodynamics and its efficacy in attenuating the response to endotracheal intubation in patients with coronary artery disease. Anesth Analg 1998; 87: 808-11.

12. Cheong KF, Wong WH. Pain on injection of rocuronium: influence of two doses of lidocaine pretreatment. Br J Anaesth 2000; 84: 106-7.

13. Klement W, Arndt JO. Pain on i.v. injection of some anaesthetic agents is evoked by the unphysiological osmolality or $\mathrm{pH}$ of their formulations. Br J Anaesth 1991; 66: 189-95. 
14. Kim KS, Kim YS, Jeon WJ, Yeom JH. Prevention of withdrawal associated with the injection of rocuronium in adults and children. J Clin Anesth 2006; 18: 334-8.

15. Park JT, Choi JC, Yoo YS, Lee YB, Kim SY, Lim HK. The effect of pretreatment with thiopental on reducing pain induced by rocuronium injection. Yonsei Med J 2005; 46: 765-8.

16. Tuncali B, Karci A, Tuncali BE, Mavioglu O, Olguner CG, Ayhan S, et al. Dilution of rocuronium to $0.5 \mathrm{mg} / \mathrm{ml}$ with $0.9 \% \mathrm{NaCl}$ eliminates the pain during intravenous injection in awake patients. Anesth Analg 2004; 99: 740-3.

17. Sakuraba S, Serita R, Kosugi S, Eriksson LI, Lindahl SG, Takeda
J. Pretreatment with magnesium sulphate is associated with less succinylcholine-induced fasciculation and subsequent tracheal intubation-induced hemodynamic changes than precurarization with vecuronium during rapid sequence induction. Acta Anaesthesiol Belg 2006; 57: 253-7.

18. Figueredo E, Garcia-Fuentes EM. Assessment of the efficacy of esmolol on the haemodynamic changes induced by laryngoscopy and tracheal intubation: a meta-analysis. Acta Anaesthesiol Scand 2001; 45: 1011-22.

19. Alexander R, Binns J, Hetreed M. A controlled trial of the effects of esmolol on cardiac function. Br J Anaesth 1994; 72: 594-5. 